\title{
The Effects of Metallurgical Factors on PWSCC Crack Growth Rates in TT Alloy 690 in Simulated PWR Primary Water
}

\begin{abstract}
TOSHIO YONEZAWA, MASASHI WATANABE, and ATSUSHI HASHIMOTO
Primary water stress corrosion cracking growth rates (PWSCCGRs) in highly cold-worked thermally treated (TT) Alloy 690 have been recently reported as exhibiting significant heat-toheat variability. Authors hypothesized that these significant differences could be due to the metallurgical characteristics of each heat. In order to confirm this hypothesis, the effect of fundamental metallurgical characteristics on PWSCCGR measurements in cold-worked TT Alloy 690 has been investigated. The following new observations were made in this study: (1) Microcracks and voids were observed in or near eutectic crystals of grain boundary (GB) $\mathrm{M}_{23} \mathrm{C}_{6}$ carbides (primary carbides) after cold rolling, but were not observed before cold rolling. These primary carbides with microcracks and voids were observed in both lightly forged and as-cast and cold-rolled TT Alloy 690 (heat A) as well as in a cold-rolled TT Alloy 690 (heat Y) that simulated the chemical composition and carbide banded structure of the material previously tested by Paraventi and Moshier. However, this was not observed in precipitated (secondary) $\mathrm{M}_{23} \mathrm{C}_{6} \mathrm{~GB}$ carbides in heavily forged and cold-rolled TT Alloy 690 heat A and a cold-rolled commercial TT Alloy 690. (2) From microstructural analyses carried out on the various TT Alloy 690 test materials before and after cold rolling, the amount of eutectic crystals (primary carbides and nitrides) $\mathrm{M}_{23} \mathrm{C}_{6}$ and TiN depended on the chemical composition. In particular, the amount of $\mathrm{M}_{23} \mathrm{C}_{6}$ depended on the fabrication process. Microcracks and voids in or near the $\mathrm{M}_{23} \mathrm{C}_{6}$ and TiN precipitates were generated by the cold rolling process. (3) The PWSCCGRs observed in TT Alloy 690 were different for each heat and fabrication process. The PWSCCGR decreased with increasing Vickers hardness of each heat. However, for the same heats and fabrication processes, the PWSCCGR increased with increasing Vickers hardness due to cold work. Thus, the PWSCCGR must be affected not only by hardness (or equivalently the cold working ratio) but also by grain size, microcracks, and voids of primary $\mathrm{M}_{23} \mathrm{C}_{6}$ carbides, etc., which in turn depend on chemical composition and the fabrication process.
\end{abstract}

DOI: $10.1007 / \mathrm{s} 11661-015-2852-1$

(C) The Author(s) 2015. This article is published with open access at Springerlink.com

\section{INTRODUCTION}

THE predecessor of TT Alloy 690 used extensively in the primary coolant circuits of PWRs, mill-annealed (MA) Alloy 600, was originally developed in the 1950s as an alternative material to austenitic stainless steel for steam generator (SG) tubing based because of its high resistance to stress corrosion cracking (SCC) in chloride solutions. ${ }^{[1]}$ However, as early as 1959 , Coriou ${ }^{[2-5]}$ reported the SCC susceptibility of some nickel-rich, iron-nickel-chromium alloys in high temperature, highpurity water. Since then, many studies ${ }^{[6-8]}$ have detected SCC in Alloy 600 and its compatible weld metals in PWR primary water environments. This particular type of (intergranular) SCC has habitually been called

TOSHIO YONEZAWA, Professor, and MASASHI WATANABE, Associate Professor, are with the FRI, New Industry Creation Hatchery Center (NICHe), Tohoku University, 6-6-10, Aoba, Aramaki, Aoba-ku, Sendai 980-8579, Japan. Contact e-mail: t-yonezawa@fri.niche. tohoku.ac.jp ATSUSHI HASHIMOTO, Research Engineer, is with the Kobe Material Testing Laboratory Co., Ltd., 47-13, Niijima, Harima-cho, Kako-Gun 675-0155, Japan.

Manuscript submitted September 9, 2014.

Article published online March 31, 2015 primary water SCC (PWSCC). In the 1970s, thermally treated (TT) Alloy 600 was developed to improve the PWSCC resistance of MA Alloy 600. However, PWSCC was also eventually detected in TT Alloy 600, initially in highly strained mechanical plugs for SG tubes.

Yonezawa et al. ${ }^{[9]}$ participated in the original development of high temperature MA TT Alloy 690 as an alternative material to MA and TT Alloy 600 for SG tubing. This was based on its high resistance to SCC in simulated PWR primary water and in highly caustic environments, etc. ${ }^{[9,10]}$ Thin section, small diameter tubing such as SG tubes is fabricated by a cold finishing process, whereas relatively thick and large diameter pipes or forged materials, such as control rod drive mechanism (CRDM) nozzles, etc., are fabricated by a hot finishing process. ${ }^{[11]}$ TT Alloy 690 has since been used not only for cold-finished materials such as SG tubes but also for hotfinished materials for several components of the pressure boundaries of PWR primary coolant systems, such as CRDM adapter nozzles, reactor vessel nozzles, etc., due to their excellent resistance to PWSCC. ${ }^{[12]}$

Up until the time of this writing, no PWSCC has been reported in any TT Alloy 690 component or its welded joints in PWR primary circuits (except SG tubes) after 
more than 15 years of operational experience worldwide.

However, in recent years, Arioka ${ }^{[13]}$ and Paraventi and Moshier $^{[14]}$ have reported PWSCC growth rates (PWSCCGRs) in highly cold-worked TT Alloy 690 up to about $1 / 5$ to $1 / 10$ of those observed in Alloy 600 , which are not negligible. These reports have had a considerable impact on PWR fabricators, owners, and regulatory authorities and have been followed up by several other investigations ${ }^{[15-21]}$ that have expanded greatly the range of observations and even observed PWSCCGRs in cold-worked TT Alloy 690 in the upper quartile of those in Alloy 600.

The reported microstructure of TT Alloy 690 by Paraventi and Moshier ${ }^{[14]}$ was significantly different from the normal microstructure of TT Alloy 690 for CRDM adapter nozzles observed by authors and coworkers, ${ }^{[22]}$ as shown in Figure 1. It is noteworthy that the size of grain boundary (GB) carbides for TT Alloy 690 used by Paraventi and Moshier ${ }^{[14]}$ is much larger than that of our TT Alloy 690. In addition, Paraventi and Moshier ${ }^{[14]}$ reported the presence of a banded structure together with large chromium carbides along grain boundaries (GBs) before cold working in their TT Alloy 690 test material, as shown in Figure 2.

Alloy 690 is a 30 pct chromium-nickel-base alloy in which solidification segregation can be quite extensive, as is characteristic of all high chromium-nickel-based alloys. It is well known that the liquidus and solidus lines are very close in the nickel-chromium phase equilibria such that a low chromium phase crystallizes in the initial stage of solidification, after which a high chromium phase crystallizes during the final stages of solidification, as shown in Figure 3.

The microstructural features reported by Paraventi and Moshier ${ }^{[14]}$ are not present in our TT Alloy 690 where the type, morphology, and coherency of GB carbides were quality controlled and characterized by TEM observation. The morphology of GB precipitates in our TT Alloy 690 therefore seems to be quite different from that tested by Paraventi and Moshier. ${ }^{14]}$ Thus, authors ${ }^{[22]}$ suggested that the fabrication method used by Paraventi and Moshier ${ }^{[14]}$ was not optimized for TT Alloy 690 and that the high PWSCCGRs observed for their TT Alloy 690 probably depended upon the material microstructure. Consequently, authors ${ }^{[22]}$ hypothesized that the banded structure and the large chromium carbides observed along the GBs in the TT Alloy 690 tested by Paraventi et al. could depend on differences in chemical composition, fabrication process, etc.

In 2009, Andresen et al. ${ }^{[15]}$ reported that PWSCCGR data measured in S-L-oriented specimens from heavily cold-worked inhomogeneous TT Alloy 690 material (This material was supplied from Argonne National Laboratory ANL.) were consistent with those obtained by Paraventi and Moshier ${ }^{[14]}$ and those data were about 100 to 1000 times greater than PWSCCGR data measured in T-L-oriented specimens from heavily cold-worked TT Alloy 690 supplied by EPRI. ${ }^{[15,21]}$

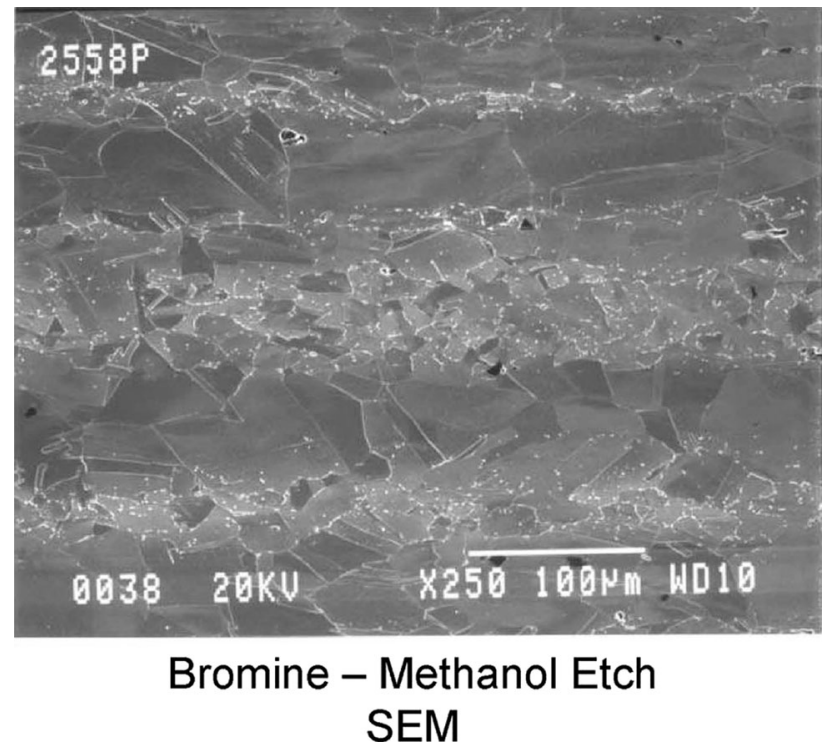

Fig. 2-The microstructure of TT Alloy 690 test materials used by Paraventi and Moshier. ${ }^{[14]}$

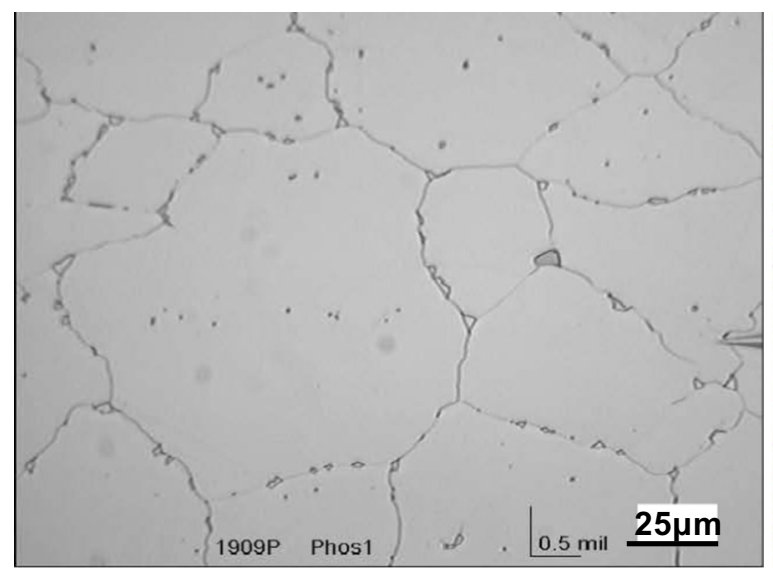

(a)

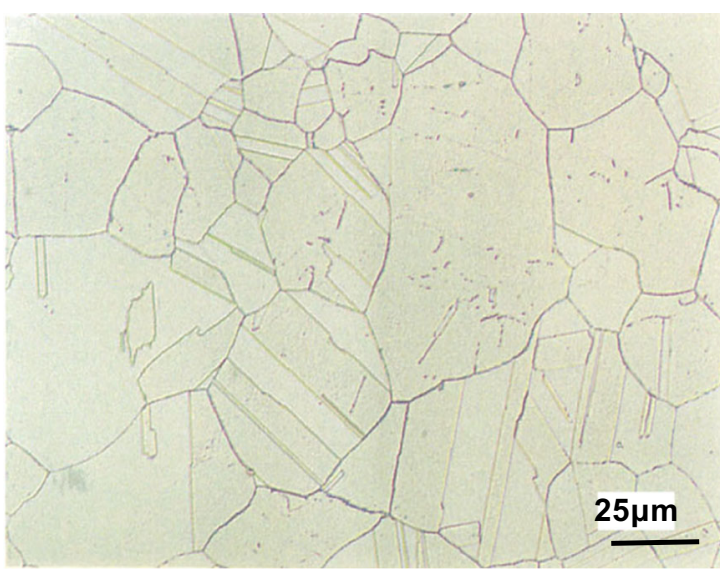

(b)

Fig. 1-Microstructure of Paraventi et al.'s TT Alloy $690^{[14]}$ and the Japanese commercial material used in this study (a) Paraventi et al. (b) Japanese commercial TT Alloy 690. 


\section{$\mathrm{Cr}-\mathrm{Ni}$}

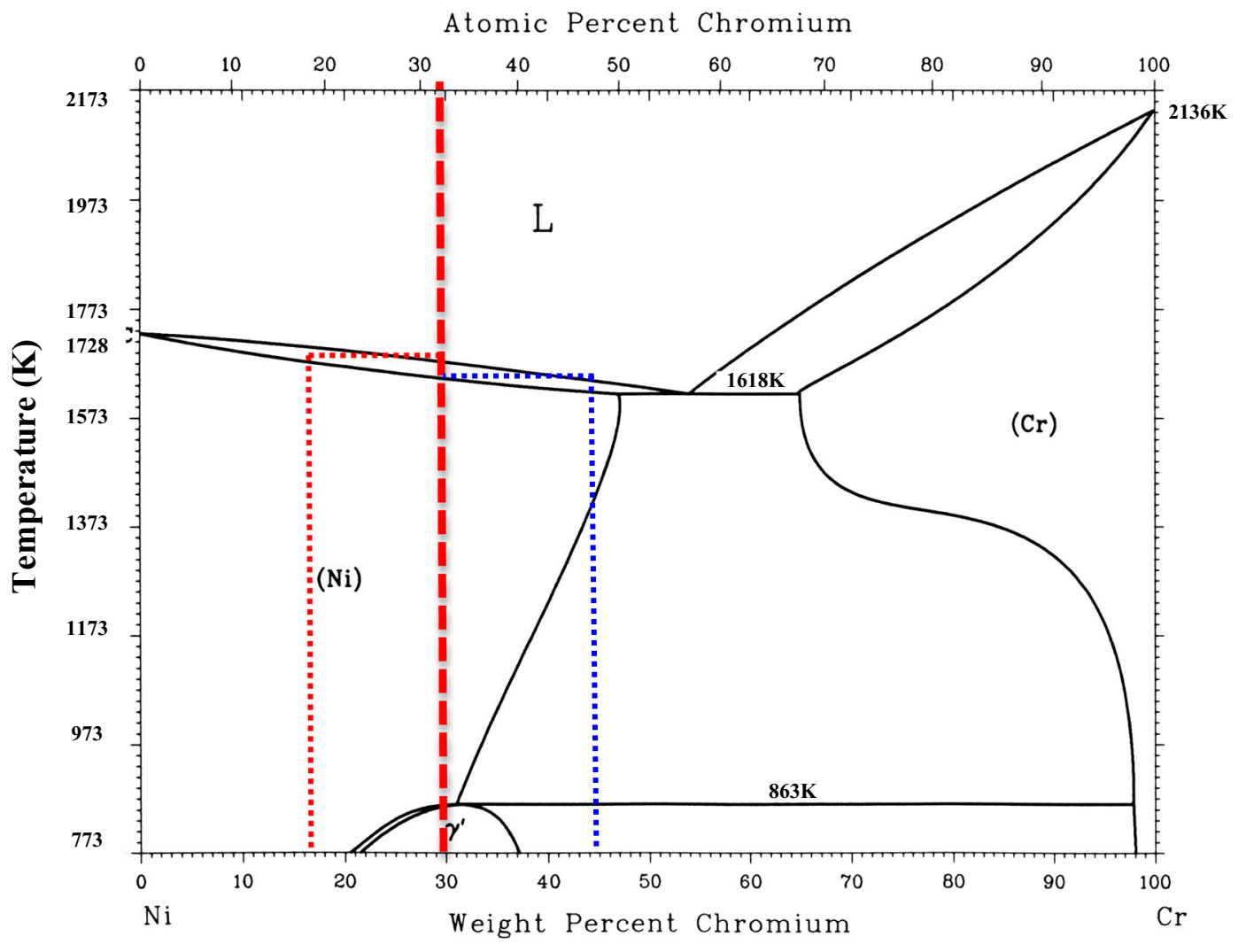

Fig. 3-Ni-Cr equilibrium phase diagram and solidification of Alloy 690.

The original (i.e., before cold work) EPRI TT Alloy 690 material was supplied by Mitsubishi Heavy Industries (MHI).

Thus, in order to confirm the possibility of PWSCC initiation and high PWSCCGRs in highly cold-worked TT Alloy 690 exposed to PWR primary water, and to clarify the mechanism of PWSCCGR, a research project was launched by the authors from the beginning of FY 2009. The basic metallurgical characteristics of such highly cold-worked TT Alloy 690 and their link, if any, to PWSCC initiation and propagation are being studied. This paper summarizes the intermediate results available from this research project.

Before starting this project, authors ${ }^{[23]}$ and co-workers performed a solidification simulation using Scheil's model. This assumes that the gamma phase crystallizes first, titanium carbo-nitrides (mainly Titanium nitride) crystallize next, and $\mathrm{M}_{23} \mathrm{C}_{6}$ carbides crystallize as eutectic carbides near the end of solidification, as shown in Figure 4. ${ }^{[24]}$ The authors have investigated the behavior of crystallized $\mathrm{M}_{23} \mathrm{C}_{6}$ carbides in various heats of TT Alloy 690 and with various fabrication processes as well as the PWSCCGRs in these test materials. $\mathrm{M}_{23} \mathrm{C}_{6}$ carbides also precipitate from the solid phase during the final thermal treatment. In this paper, the crystallized $\mathrm{M}_{23} \mathrm{C}_{6}$ carbides that form during solidification are called primary carbides and those $\mathrm{M}_{23} \mathrm{C}_{6}$ carbides precipitated during thermal treatment are called secondary carbides to distinguish between them.

\section{EXPERIMENTAL PROCEDURES}

\section{A. Materials}

Four heats of laboratory-melted TT Alloy 690 and one heat of commercial TT Alloy 690 pipe for a CRDM nozzle were used in this study. The chemical compositions of these test materials were determined by ladle analyses, and are shown in Table I. In order to check the effect primarily of chromium carbides on GB precipitates, laboratory-melted Heats $\mathrm{A}, \mathrm{R}$, and $\mathrm{X}$ were selected with a low titanium content. The chemical composition of laboratory-melted Heat $\mathrm{Y}$ was selected to copy that of the TT Alloy 690 test material described in the paper by Paraventi and Moshier ${ }^{[14]}$

The laboratory-melted heats were fabricated as $180 \mathrm{~kg}$ lots by vacuum induction melting, casting under vacuum, and then forging.

The ingots of laboratory-melted heats A, X, and Y were then cut into four pieces to which the following four post-melting fabrication processes and cold rolling were applied:

(1) SHT and TT as-cast (process A).

(2) SHT and TT after light forging (process B).

(3) SHT and TT after light forging and heavy forging (process $\mathrm{C}$ ).

(4) SHT and TT after light forging, heavy forging, intermediate heat treatment, and cold rolling (process D). 


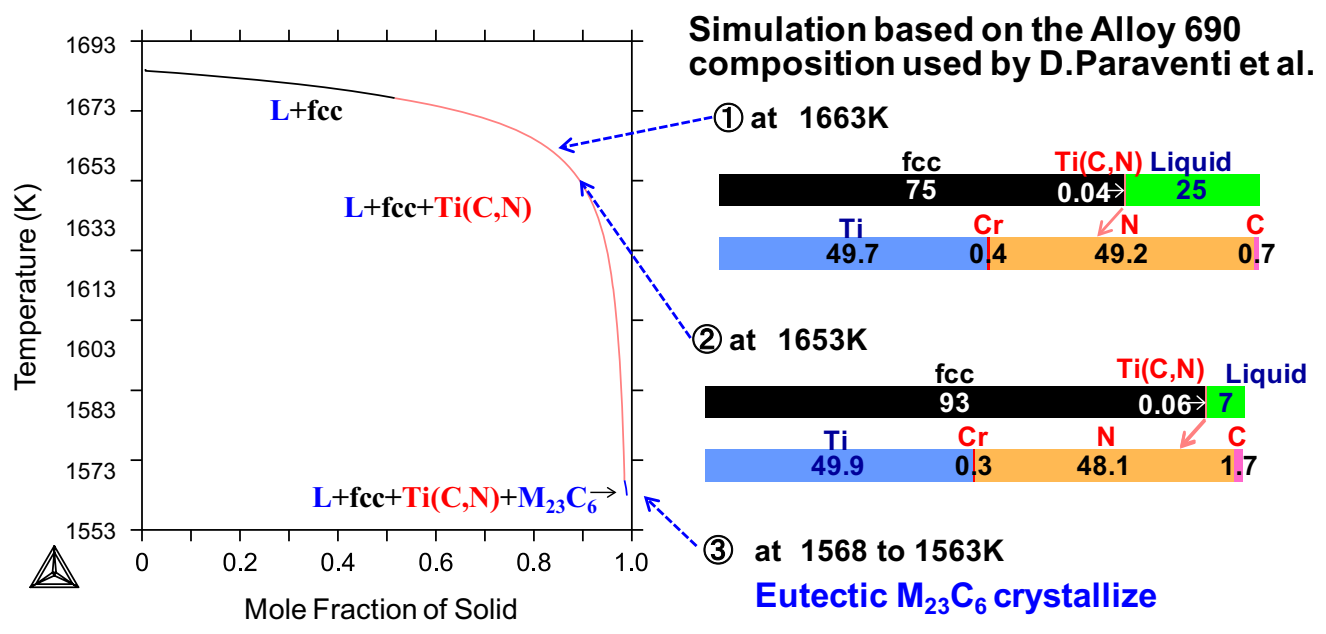

Mole fraction of constituents for $\mathrm{Ti}(\mathrm{C}, \mathrm{N})$

Fig. 4-Solidification simulation by Scheil's model for the Alloy 690 chemical composition used by Paraventi and Moshier ${ }^{[14]}$ as Ni-30Cr-9Fe$0.3 \mathrm{Ti}-0.03 \mathrm{C}-0.01 \mathrm{~N}$ (wt pet).

Table I. Chemical Compositions of the Test Materials (Ladle Analyses)

\begin{tabular}{|c|c|c|c|c|c|c|c|c|c|c|}
\hline \multirow[b]{2}{*}{ Heat No. } & \multirow[b]{2}{*}{ Features } & \multicolumn{9}{|c|}{ Chemical Compositions (Wt Pct) } \\
\hline & & $\mathrm{C}$ & $\mathrm{Si}$ & $\mathrm{Mn}$ & $\mathrm{P}$ & $\mathrm{S}$ & $\mathrm{Ni}$ & $\mathrm{Cr}$ & $\mathrm{Ti}$ & $\mathrm{Fe}$ \\
\hline $\bar{A}$ & lab. melt & 0.026 & 0.25 & 0.31 & $<0.001$ & 0.001 & 60.14 & 30.14 & $<0.001$ & 9.30 \\
\hline $\mathrm{R}$ & lab. melt & 0.020 & 0.25 & 0.30 & 0.001 & 0.001 & 59.81 & 30.15 & $<0.001$ & 9.58 \\
\hline $\mathrm{X}$ & lab. melt & 0.019 & 0.25 & 0.30 & 0.009 & 0.001 & 60.0 & 29.9 & $<0.001$ & 9.60 \\
\hline $\mathrm{Y}$ & lab. melt (simulated Paraventi's) & 0.031 & 0.04 & 0.06 & 0.003 & 0.001 & 60.60 & 29.60 & 0.34 & 9.00 \\
\hline \multicolumn{2}{|c|}{ Test material by Paraventi et al.* } & 0.031 & 0.032 & 0.05 & 0.002 & $<0.001$ & 60.61 & 29.63 & 0.34 & 8.89 \\
\hline \multicolumn{2}{|c|}{ Test material by Arioka et al.** } & 0.021 & 0.33 & 0.34 & 0.011 & 0.0002 & 59.12 & 30.28 & NR & 9.42 \\
\hline $\mathrm{S}$ & Commercial Heat for CRDM Pipe & 0.020 & 0.25 & 0.29 & 0.008 & 0.002 & 59.39 & 29.80 & 0.21 & 9.88 \\
\hline
\end{tabular}

In the case of the laboratory-melted heat $\mathrm{R}$, after casting into an ingot, the following hot working process was applied:

(5) SHT and TT after light forging, heavy forging, and hot rolling (process $\mathrm{E}$ ).

The commercial TT Alloy 690 for a CRDM nozzle was fabricated by Nippon Steel \& Sumitomo Metal Corporation in a 40 ton batch by a vacuum oxygen decarburization process followed by casting under vacuum and then hot extrusion (process $\mathrm{P}$ ).

All heats were solution heat treated (SHT) at $1348 \mathrm{~K}$ for 1 hour and TT at $973 \mathrm{~K}\left(700{ }^{\circ} \mathrm{C}\right)$ for 15 hours after each forging process. The test materials were prepared by one-directional cold rolling to $30 \mathrm{pct}$ or $15 \mathrm{pct}$ reduction $\sim$ of $25-\mathrm{mm}$-thick plates from the laboratory heats and $\sim 25-\mathrm{mm}$-thick slabs machined from the commercial TT Alloy 690 CRDM nozzle. Due to the relatively low load capacity of the 500 ton press available, multiple passes of $\sim 100$ or 50 times were applied to the laboratory heats and commercial material, respectively.

\section{B. PWSCC Test and Crack Growth Rate Measurements}

It is well known that the $\mathrm{S}-\mathrm{L}$ orientation is susceptible to SCCGR for heavily cold-rolled material. But, the susceptibility of S-L orientation is not directly related to the SCC phenomenon of practical component. From the viewpoint of practical designing, fabricating, and maintaining, most important SCC data are for T-L or T-S orientation, not for S-L orientation.

And also, in order to study on the effect of fabrication process for laboratory-melted heats, it is impossible to fabricate the thick product for laboratory-melted heats, because the ingot of laboratory heat is very small.

So, for the PWSCCGR measurements in this study, $0.7 \mathrm{~T}$ compact tension type (CT) specimens with side grooves in the $\mathrm{T}-\mathrm{L}$ orientation were selected and machined from the 30 or 15 pct one directionally coldrolled plates of the TT Alloy 690 test materials.

The CT specimens were fatigue pre-cracked in air using sine wave loading at $30 \mathrm{~Hz}$ and a $K_{\max }$ value of $15 \mathrm{MPa} \sqrt{\mathrm{m}}$ with a load ratio $\left(K_{\min } / K_{\max }\right) R=0.3 \mathrm{up}$. After pre-cracking in air, the specimens were subjected 


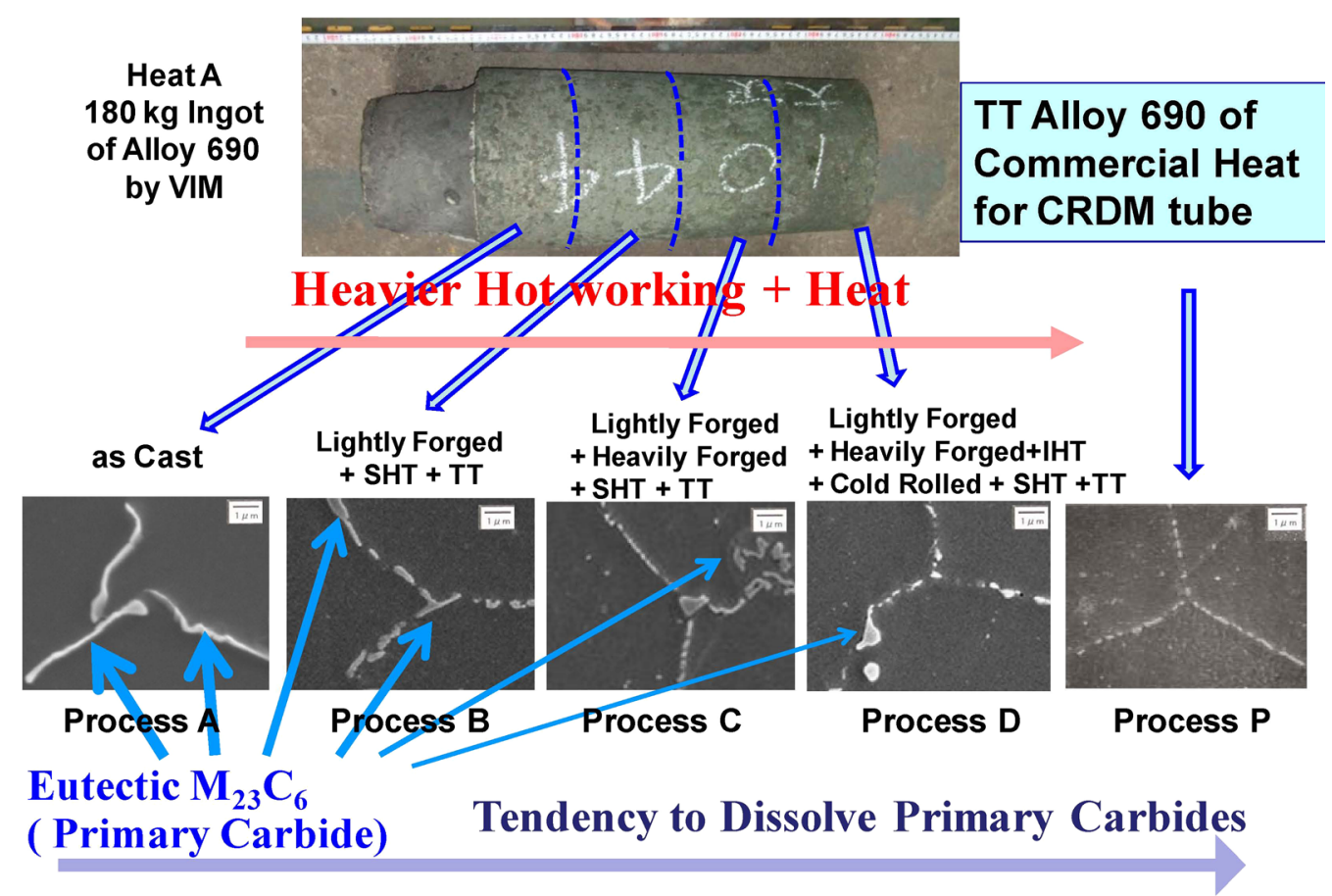

SHT: solution heat treatment, IHT: intermediate heat treatment

Fig. 5-The effect of hot working processes on grain boundary primary carbides in TT Alloy 690 heat A.

to further in situ triangular wave fatigue pre-cracking at $623 \mathrm{~K}$ or $633 \mathrm{~K}\left(350{ }^{\circ} \mathrm{C}\right.$ or $\left.360^{\circ} \mathrm{C}\right)$ in simulated PWR primary water $\left(\mathrm{H}_{3} \mathrm{BO}_{3}: 1200 \mathrm{ppm}\right.$ as $\mathrm{B}$, LiOH: $3.0 \mathrm{ppm}$ as $\mathrm{Li}$, dissolved oxygen $<5 \mathrm{ppb}$, dissolved hydrogen $=30 \mathrm{cc} / \mathrm{kg} \mathrm{STP} \mathrm{H}_{2} \mathrm{O}$ ). The triangular wave loading for the in situ pre-cracking was conducted in a series of steps: Step (1) $f=0.01 \mathrm{~Hz}, K_{\max }=30 \mathrm{MPa} \sqrt{\mathrm{m}}$, $R=0.3$, during 100 hours; Step (2) $f=0.01 \mathrm{~Hz}$, $K_{\max }=30 \mathrm{MPa} \sqrt{\mathrm{m}}, R=0.5$, during 24 hours; and Step (3) $f=0.01 \mathrm{~Hz}, K_{\max }=30 \mathrm{MPa} \sqrt{\mathrm{m}}, \quad R=0.7$, during 24 hours. After this fatigue pre-cracking procedure, a trapezoidal wave loading mode was applied as step (4) $f=0.01 \mathrm{~Hz}, K_{\max }=30 \mathrm{MPa} \sqrt{\mathrm{m}}, \quad R=0.7$, holding time at $K_{\max }=3600$ seconds for 100 hours. Subsequently, each specimen was held at a constant stress intensity of $30 \mathrm{MPa} \sqrt{\mathrm{m}}$.

The crack length in each specimen was continuously monitored by a direct current potential drop technique linked to a data-logging system. All crack lengths were calibrated against the actual values measured on the fracture surfaces at the end of the test when the specimens were broken open.

\section{TEST RESULTS AND DISCUSSION}

\section{A. Effect of Fabrication Process on GB Carbide Morphology, Carbide Coherency, Voids, Cracks, etc.}

In order to study the effect of the fabrication processes on GB carbide morphology and coherency in TT Alloy 690 as well as to determine whether voids or cracks were present in or near GB carbides in the case of highly cold-worked TT Alloy 690, scanning electron microscopy was conducted on all test material slabs after processes A, B, C, D, and E for laboratory-melted heats $\mathrm{A}, \mathrm{R}, \mathrm{X}$, and $\mathrm{Y}$, and process $\mathrm{P}$ for the commercial heat $\mathrm{S}$.

30 or 15 pct one-directional cold rolling was applied to the slabs after SHT and TT. The microstructures associated with the hot working processes of each of the test material slabs are compared with that of the CRDM nozzle commercial heat TT Alloy 690 in Figure 5. Large carbides (greater than several microns) were observed in the as-cast TT Alloy 690. These large carbides were deduced to be primary carbides that were then redissolved and changed to small (secondary) carbides during the various hot working and inter-pass heat treatments and cold working. In the CRDM nozzle commercial TT Alloy 690, primary carbides were nonexistent, and only tiny carbides (smaller than half a micron) were detected. These tiny carbides were deduced to be secondary carbides that precipitated during the thermal treatment. From the TEM examinations, it was confirmed that the large primary carbides crystallized along the grain boundaries as eutectic film-like carbides at the end of solidification, whereas the secondary carbides precipitated epitaxially along the grain boundaries during the TT after solution heat treatment. The primary $\mathrm{M}_{23} \mathrm{C}_{6}$ carbides were incoherent with the metal matrix in the TT Alloy 690 but secondary $\mathrm{M}_{23} \mathrm{C}_{6}$ carbides were basically coherent with metal matrix, as shown in Figure 6.

Arioka et al..$^{[1,25]}$ have reported that cracked carbides and cavities were observed in intergranular locations on the periphery of the tips of both IGSCC and creep cracks in cold-worked TT Alloy 690. These cavities were assumed to have formed before the stress corrosion or 


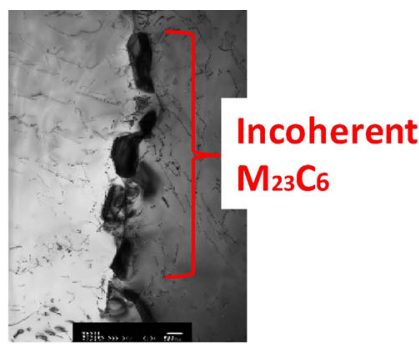

Lightly Forged + SHT + TT
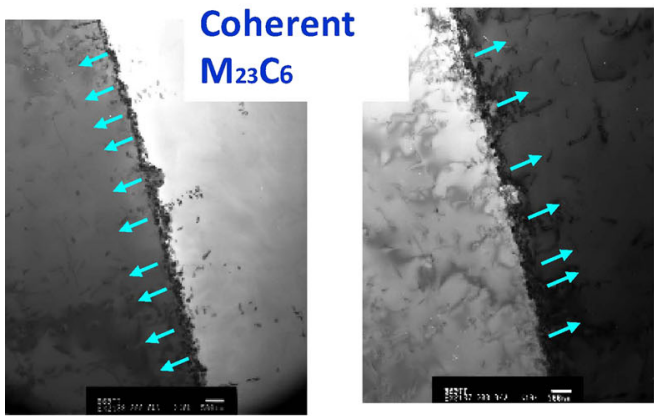

Lightly Forged + Heavily Forged + IHT + Cold Rolled + SHT + TT

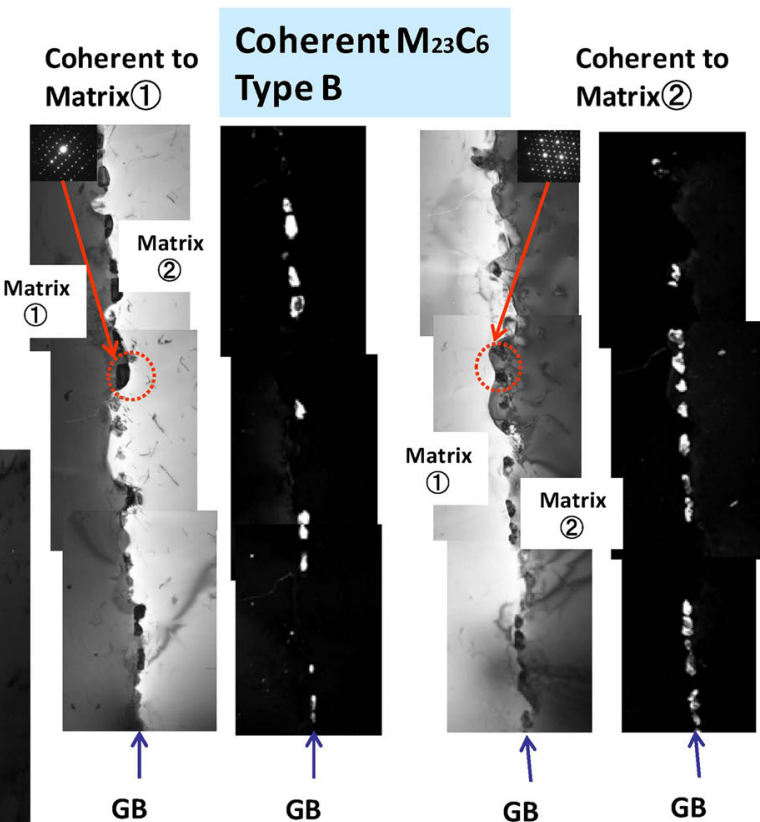

Lightly Forged + Heavily Forged+ $\mathrm{SHT}+\mathrm{TT}$

Fig. 6-Morphology, coherency, and type of carbides formed along grain boundaries in lightly forged and heavily forged TT Alloy 690.

creep cracks advanced and seemed to be involved in the crack growth processes as crack embryos. These embryos were considered to have nucleated by the condensation of vacancies.

In the present work, using scanning electron microscopy combined with ion etching, cracks and voids were detected in the primary carbides and nitrides in the lightly forged slab of TT Alloy 690 Heat A after 30 pct cold rolling, but were not detected before 30 pct cold rolling, as shown in Figure 7. These results showed good agreement with those of Bruemmer et al. ${ }^{[26]}$ These observations are evidence that the hypothesis for the formation of cavities by Arioka et al. ${ }^{[13,25]}$ may not be correct.

In the case of the heavily forged slab of TT Alloy 690 Heat A, primary carbides were hardly ever observed, and cracks and voids were not detected either before or after 30 pet cold rolling, as shown in Figure 7. This result implies that the cracks and voids observed in GB carbides in the lightly forged materials after 30 pct cold rolling must have occurred in the primary carbides at the time of cold rolling.

In the case of the TT Alloy 690 Heat Y that simulated the material used by Paraventi et al. ${ }^{[14]}$ large primary carbides were detected along the GBs and cracked carbides and voids were observed in these primary carbides after 30 pct cold rolling despite heavy forging. Large primary carbides along the GBs, cracked TiN particles, and banded carbide structures were also observed, as shown in Figure 8.

From the above results, the following description of the sequence of microstructural events during casting, forging, heat treatment, and cold rolling was deduced, as shown in Figure 9.
(1) Film-like eutectic $\mathrm{M}_{23} \mathrm{C}_{6}$ (primary) carbides crystallized along GBs at the final stage of solidification. Eutectic TiN nitrides particles formed intragranularly.

(2) Primary carbides partially dissolved into the matrix during light forging.

(3) Tiny $\mathrm{M}_{23} \mathrm{C}_{6}$ (secondary) carbides precipitated during thermal treatment after solution heat treatment.

(4) Cracks and voids formed in the large remaining $\mathrm{M}_{23} \mathrm{C}_{6}$ primary GB carbides and TiN nitrides during 30 pct cold rolling but not in the tiny $\mathrm{M}_{23} \mathrm{C}_{6}$ secondary GB carbides.

(5) Depending on the chemical composition, primary carbides mostly dissolved into the matrix during heavy forging and inter-pass heat treatments.

(6) Tiny $\mathrm{M}_{23} \mathrm{C}_{6}$ secondary carbides also precipitated by thermal treatment after solution heat treatment in the heavily forged material.

(7) Microcracks and voids did not form in the tiny $\mathrm{M}_{23} \mathrm{C}_{6}$ secondary carbides along GBs during 30 pct cold rolling of the heavily forged material.

Thus, cracked carbides and voids must have formed in or near eutectic carbides and nitrides during cold rolling before any of the PWSCC tests.

\section{B. Effect of Fabrication Processes on PWSCCGRs}

The PWSCCGR measurement tests were conducted at $623 \mathrm{~K}$ and $633 \mathrm{~K}\left(350{ }^{\circ} \mathrm{C}\right.$ and $\left.360{ }^{\circ} \mathrm{C}\right)$ in simulated PWR primary water for both the laboratory-melted heats and commercial heat of TT Alloy 690 after 30 or 15 pct cold rolling. Table II shows the PWSCCGR test 


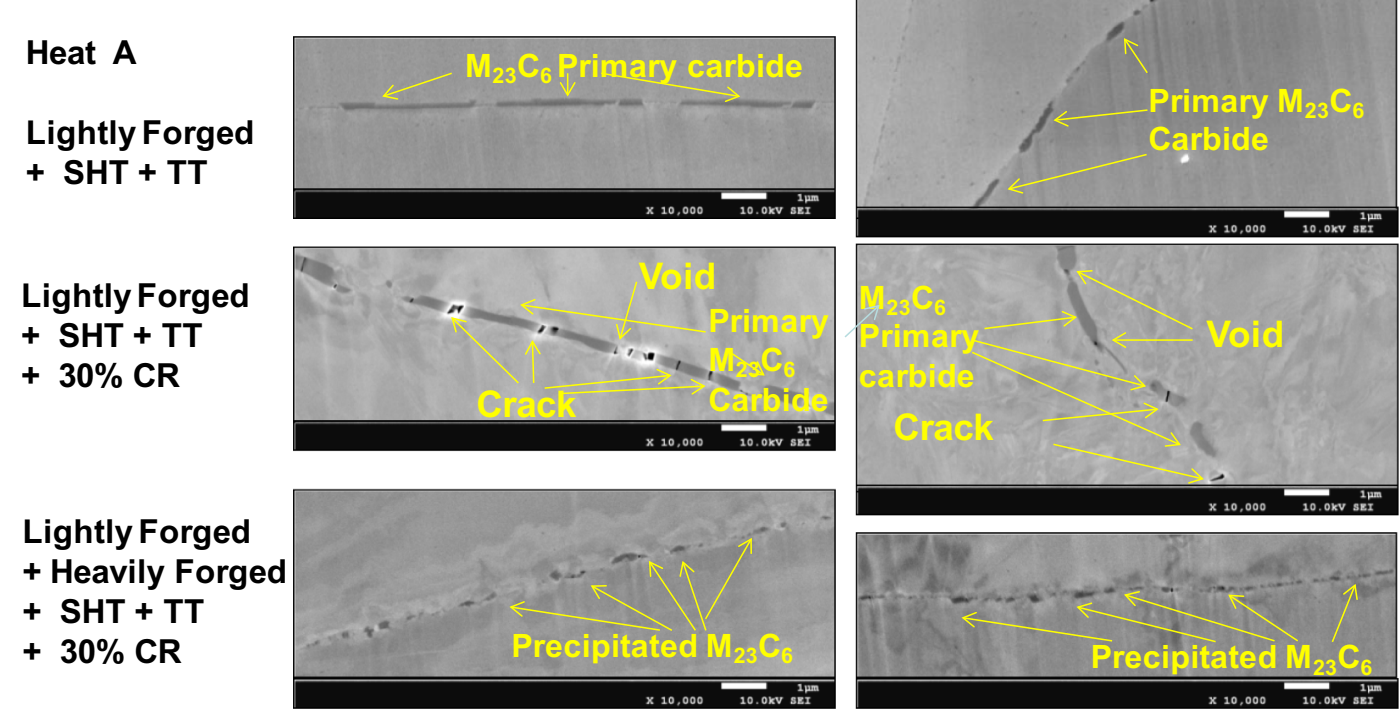

Fig. 7-The effect of hot working processes on cracks and voids at grain boundary carbides in TT Alloy 690 heat A.

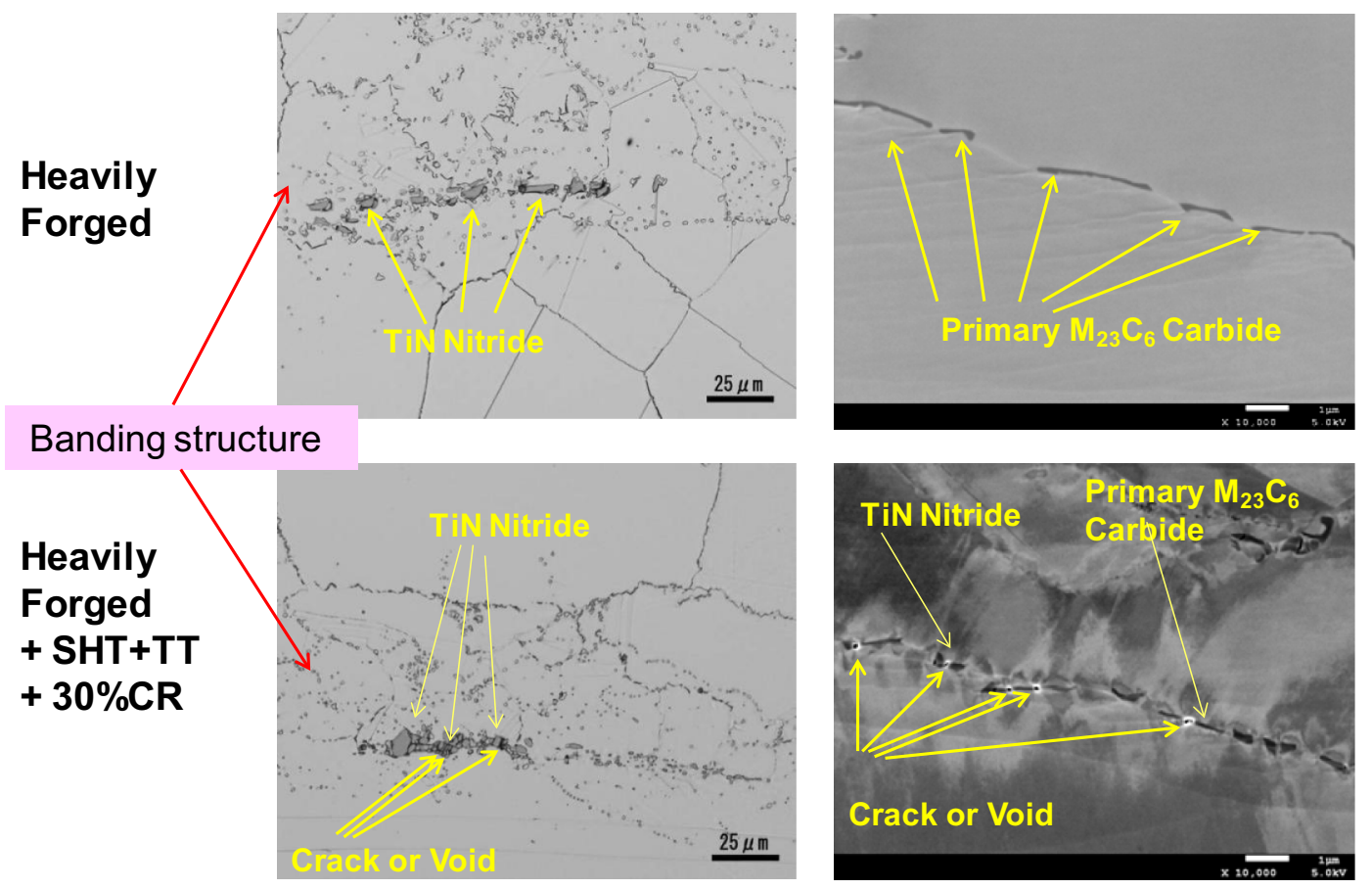

Fig. 8- Microstructure of the TT Alloy 690 heat Y that simulated the material tested by Paraventi and Moshier. ${ }^{[14]}$

matrix used in this study. The test matrix in the italicized zone of Table II shows PWSCCGR measurement test results at $633 \mathrm{~K}\left(360{ }^{\circ} \mathrm{C}\right)$. The PWSCCGR for each specimen was monitored by the DCPD system and subsequently corrected by the results of fracture surface measurements after each PWSCCGR test. Figure 10 shows typical fracture appearance and scanning electron microscopy image after SCCGR tested specimen. From this figure, it was identified that the fatigue pre-crack in air was about 1.5 to $2 \mathrm{~mm}$, and environmental fatigue was about $0.6 \mathrm{~mm}$. The Vickers hardness of each CT specimen was measured with a $10 \mathrm{~kg}$ load on a cross section near the notch front after each PWSCCGR test.

Figure 11 shows the PWSCC maximum CGRs measured in 30 pet cold-rolled TT Alloy 690 at $623 \mathrm{~K}$ $\left(350^{\circ} \mathrm{C}\right)$ in simulated PWR primary water $v s$ the Vickers hardness of each specimen. From this figure, it appears that the PWSCCGR of TT Alloy 690 decreases with the increasing Vickers hardness, which is contrary to the usual perception of the effect of material strength on SCCGR. ${ }^{[26]}$ The specimen that showed the highest PWSCCGR had not only the lowest Vickers hardness 
but also the largest grain size and was machined from the material subjected to process A (as cast + SHT + TT +30 pct cold rolled). The PWSCCGR decreased, and Vickers hardness decreased in the order of the fabrication processes A, B, C, D, E and P. The hot working ratio increased in the same order, whereas the remaining density of primary carbides decreased in the same order of the fabrication processes A, B, C, D, E, and $\mathrm{P}$.

A correlation was also observed between the PWSCCGRs and a composite parameter of the Vickers hardness values multiplied by the square root of the austenite grain sizes, as shown in Figure 12. Thus, it is deduced that the PWSCCGR of TT Alloy 690 changes not only as a function of hardness but also according to the grain size.

Figure 13 shows the PWSCCGR vs Vickers hardness of all specimens examined in this study. The PWSCCGR of the commercial heat of TT Alloy 690 at $633 \mathrm{~K}$ $\left(360{ }^{\circ} \mathrm{C}\right)$ was not so different from that of the

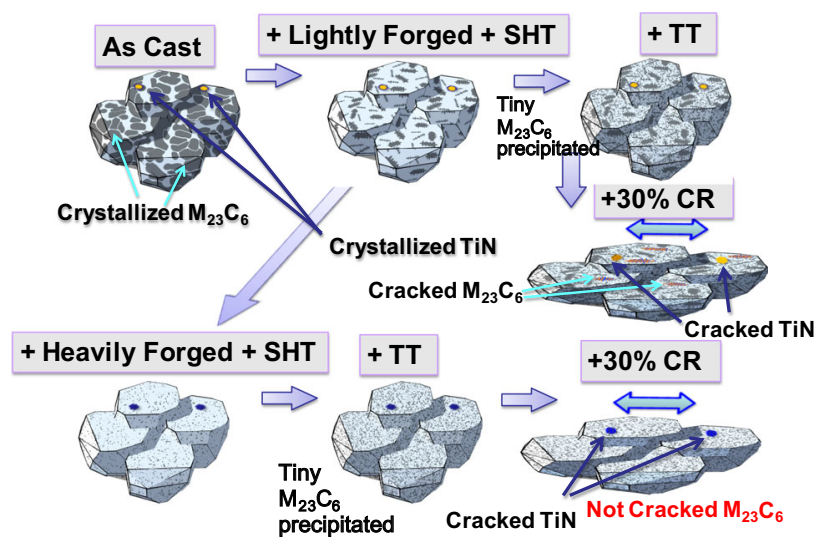

Fig. 9-Proposed mechanism for producing cracked $\mathrm{M}_{23} \mathrm{C}_{6}$ carbides and intact $\mathrm{M}_{23} \mathrm{C}_{6}$ carbides and TiN nitrides near grain boundaries for TT Alloy 690.
PWSCCGR of the same heat of TT Alloy 690 observed at $623 \mathrm{~K}\left(350^{\circ} \mathrm{C}\right)$ in simulated PWR primary water.

The 15 pct cold-rolled material showed a low PWSCCGR compared to the 30 pct cold-rolled material, especially in the case of the commercial heat of TT Alloy 690. The difference between PWSCCGRs of the 15 pct cold-rolled material and 30 pct cold-rolled material of laboratory-melted heat $\mathrm{X}$ was smaller than that of the commercial heat of TT Alloy 690. In the case of the laboratory-melted heat $\mathrm{Y}$, the 15 pct cold-rolled material did not show any large difference in PWSCCGR compared to the $30 \mathrm{pct}$ cold-rolled material. The laboratory-melted Heat Y showed a high PWSCCGR despite the heavy forging ratio. The chemical composition of laboratory-melted Heat $\mathrm{Y}$ is simulated to the chemical composition of TT Alloy 690 used by Paraventi and Moshier. ${ }^{[14]}$ But, Paraventi et al. reported the difference between PWSCCGRs of the 15 pct coldrolled material and 30 pct cold-rolled material. The difference between the results of Heat $\mathrm{Y}$ in this paper and the results of Paraventi et al. will be studied in future.

It is well known that the SCCGR of austenitic stainless steels and nickel-base alloys in high temperature water generally increases with the increasing strength level. ${ }^{[26]}$ From Figure 13, it is concluded that the PWSCCGR at $633 \mathrm{~K}\left(360{ }^{\circ} \mathrm{C}\right)$ of the same heat of TT Alloy 690 and same fabrication process increased with increasing of Vickers harness level, although this tendency was not so clearly seen in the laboratorymelted heat $\mathrm{Y}$.

From the microscopic observation of microcracks and voids in or near primary carbides in these materials, the number of microcracks and voids decreased in the following order: laboratory-melted heat $\mathrm{Y}$ process $\mathrm{A}$, process $\mathrm{B}$, heat $\mathrm{X}$ process $\mathrm{B}$, and commercial heat $\mathrm{S}$ process $\mathrm{P}$, as shown in Figure 14.

In this paper, these microcracks and voids in or near primary carbides were categorized into four types, as

Table II. Summary of PWSCC Growth Rate Measurements in Simulated PWR Primary Water

\begin{tabular}{lccccc}
\hline No. & Heat & Fabrication Process & Cold Work & Test Temperature $\left[\mathrm{K}\left({ }^{\circ} \mathrm{C}\right)\right]$ & Orientation of Specimen \\
\hline 1 & A & process A & 30 pct 1D cold roll & $623(350)$ & T-L \\
2 & A & process B & 30 pct 1D cold roll & $623(350)$ & T-L \\
3 & A & process C & 30 pct 1D cold roll & $623(350)$ & T-L \\
4 & A & process D & 30 pct 1D cold roll & $623(350)$ & T-L \\
5 & R & process E & 30 pct 1D cold roll & $623(350)$ & T-L \\
6 & Y & process A & 15 pct 1D cold roll & $633(360)$ & T-L \\
7 & Y & process B & 15 pct 1D cold roll & $633(360)$ & T-L \\
8 & Y & process C & 15 pct 1D cold roll & $633(360)$ & T-L \\
9 & Y & process C & 15 pct 1D cold roll & $633(360)$ & T-L \\
10 & Y & process B & 30 pct 1D cold roll & $633(360)$ & T-L \\
11 & X & process B & 15 pct 1D cold roll & $633(360)$ & T-L \\
12 & X & process C & 15 pct 1D cold roll & $633(360)$ & T-L \\
13 & X & process B & 30 pct 1D cold roll & $623(350)$ & T-L \\
14 & S & process P & 30 pct 1D cold roll & $633(360)$ & T-L \\
15 & S & process P & 15 pct 1D cold roll & $633(360)$ & T-L \\
16 & S & process P & 20 pct 1D cold roll & $633(360)$ & T-L \\
17 & S & process P & 30 pct 1D cold roll & $633(360)$ & T-L \\
18 & S & process P & 30 pct 1D cold roll & & \\
\hline
\end{tabular}




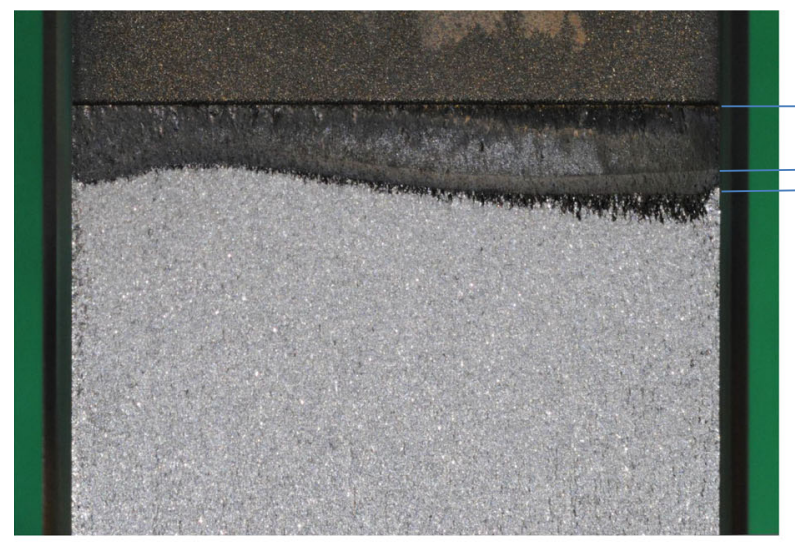

$2 \mathrm{~mm}$

$0.6 \mathrm{~mm}$

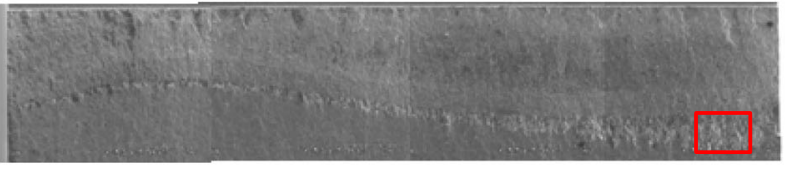

Average Crack Length : $0.20 \mathrm{~mm}$ Cracked Area : $2.66 \mathrm{~mm}^{2}$

Max. Crack Length : $0.77 \mathrm{~mm}$
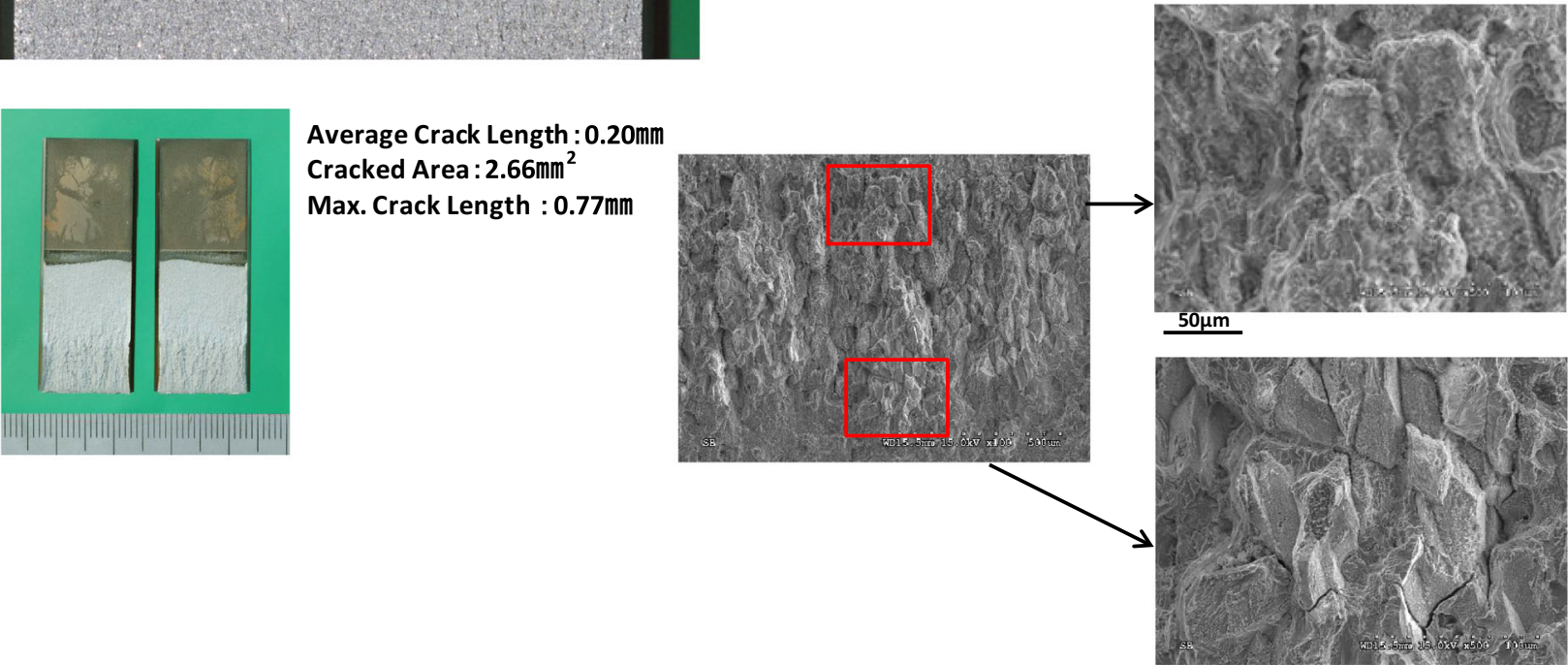

$50 \mu \mathrm{m}$

Fig. 10-Appearance of CT specimen of TT Alloy 690 commercial Heat S after SCC tested at $633 \mathrm{~K}\left(360{ }^{\circ} \mathrm{C}\right)$ temperature accelerated in simulated PWR primary water for $2714 \mathrm{~h}$. Fatigue pre-crack was given in air and at $633 \mathrm{~K}\left(360^{\circ} \mathrm{C}\right)$ in simulated PWR primary water.

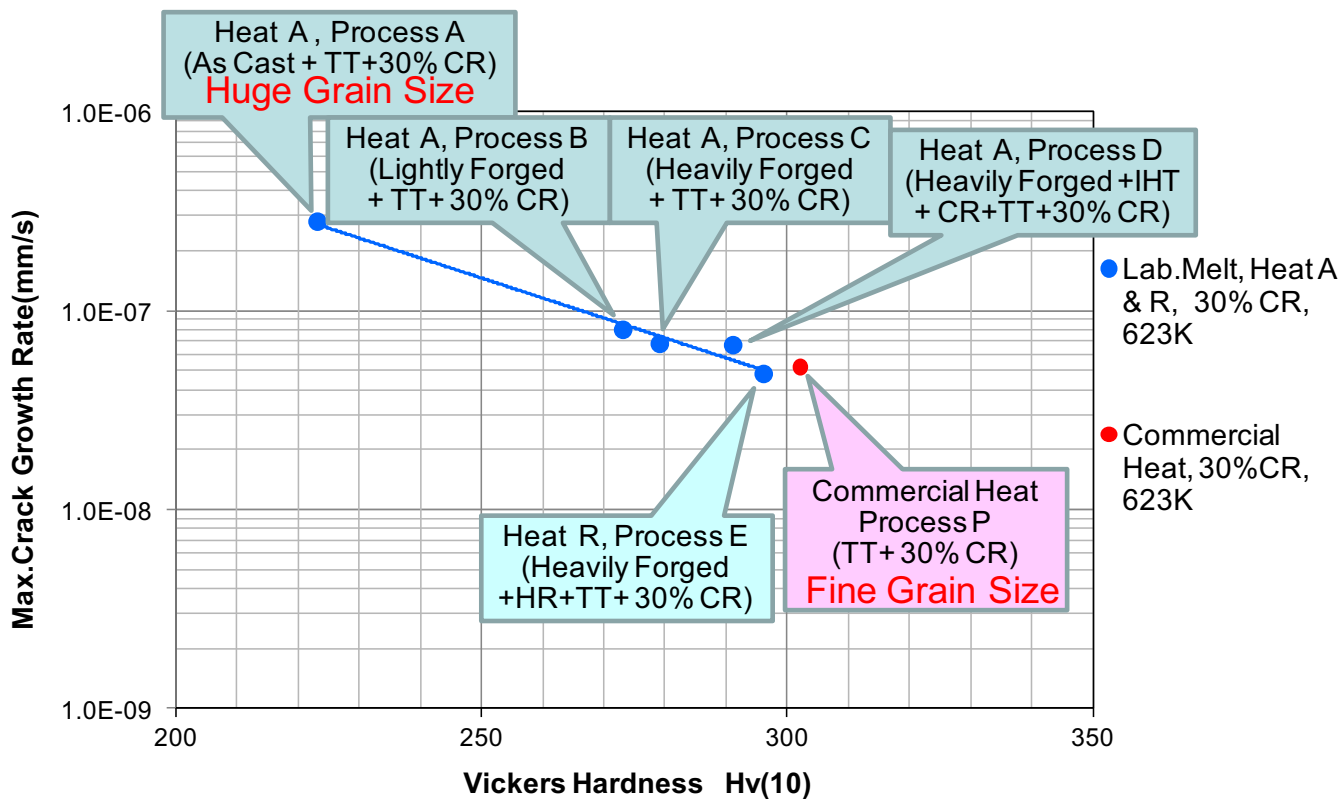

IHT : Intermediate heat treated

TT : SHT + TT

Fig. 11-Effect of hardness on maximum PWSCC growth rate in cold-worked TT Alloy 690 at $623 \mathrm{~K}\left(350{ }^{\circ} \mathrm{C}\right)$ in simulated PWR primary water. 


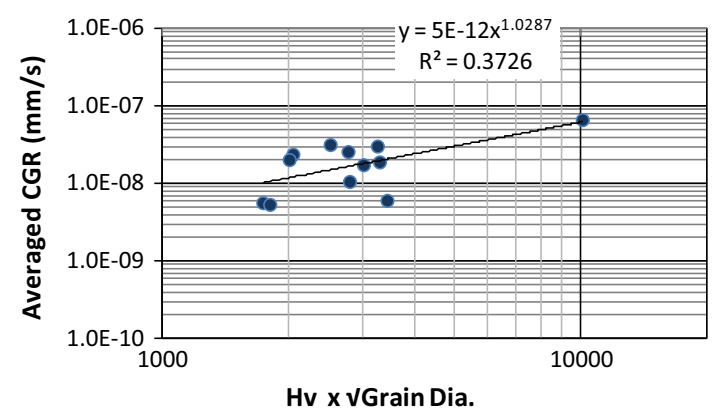

Fig. 12-Effect of hardness and grain size on averaged PWSCC growth rate in cold-worked TT Alloy 690 at $633 \mathrm{~K}\left(360^{\circ} \mathrm{C}\right)$ in simulated PWR primary water. shown in Figure 15. These categorized cracks were counted for more than seven observed locations in all specimens.

Also, the crack factor was defined as integrated the number of Type I, II, III, and 20 pct of Type IV. Figure 16 and Table III show the relationship between the hardness, grain size, and crack factor on averaged PWSCC growth rate in cold-worked TT Alloy 690 at $633 \mathrm{~K}\left(360^{\circ} \mathrm{C}\right)$ in simulated PWR primary water. From this figure, it is considered that the PWSCCGR must depend not only on cold work and grain size but also on the numbers of microcracks and voids in or near primary carbides, etc.

In this study, the authors selected one-directional cold rolling of 30 pet and 15 pet to study strain-hardened TT
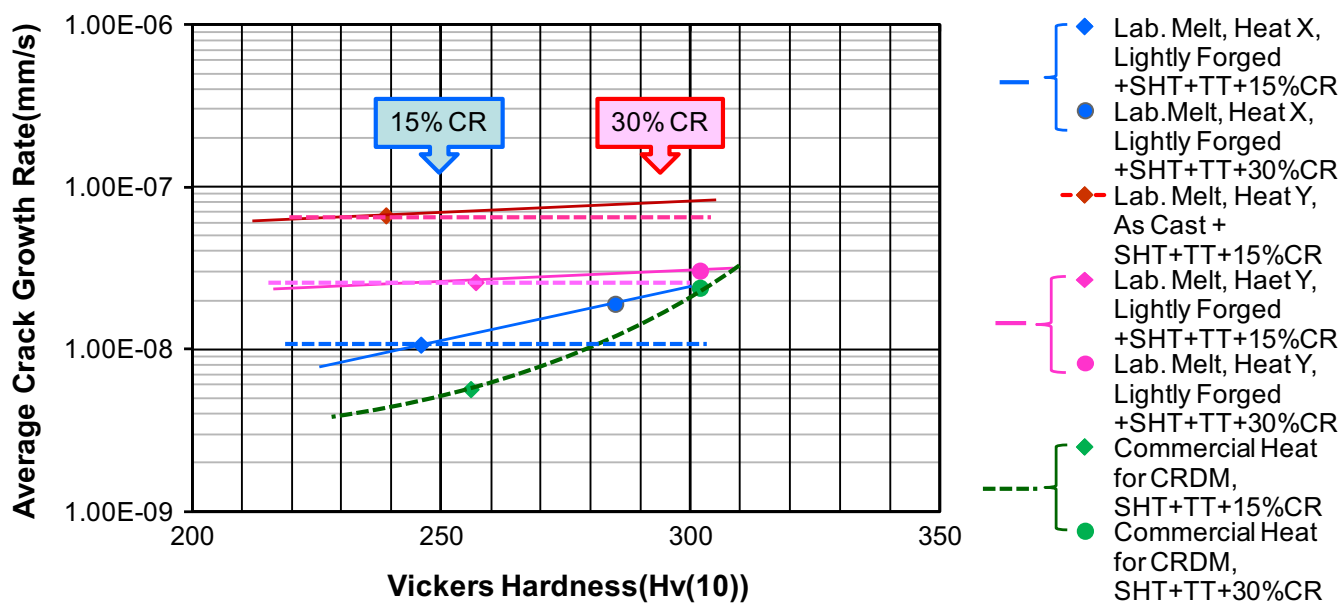

Fig. 13 - Effect of hardness on averaged PWSCC growth rate for TT Alloy 690 at $623 \mathrm{~K}$ and $633 \mathrm{~K}\left(350{ }^{\circ} \mathrm{C}\right.$ and $\left.360{ }^{\circ} \mathrm{C}\right)$ in simulated PWR primary water.

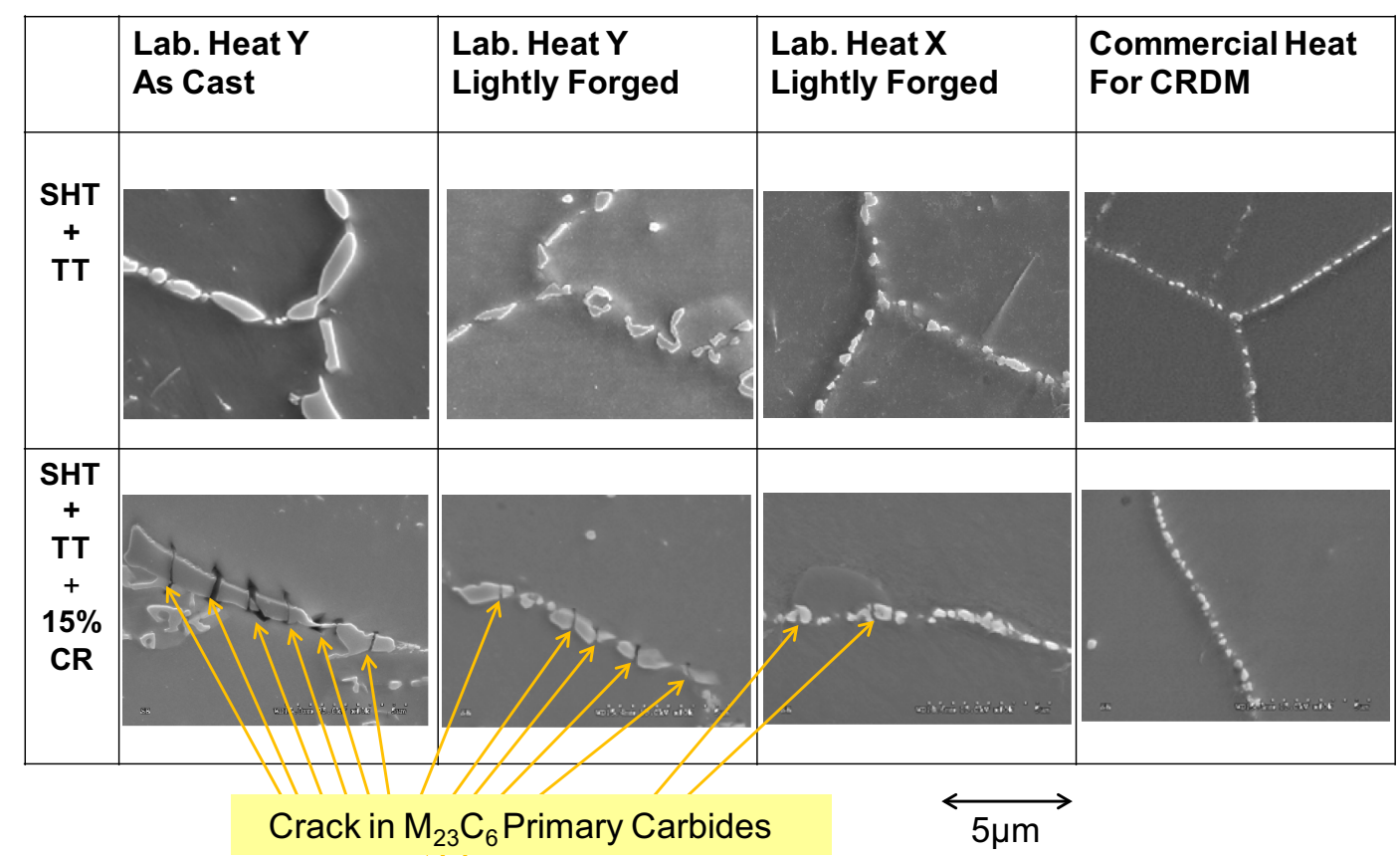

Fig. 14 - Grain boundary carbides and associated cracks in laboratory heats and a commercial heat. 


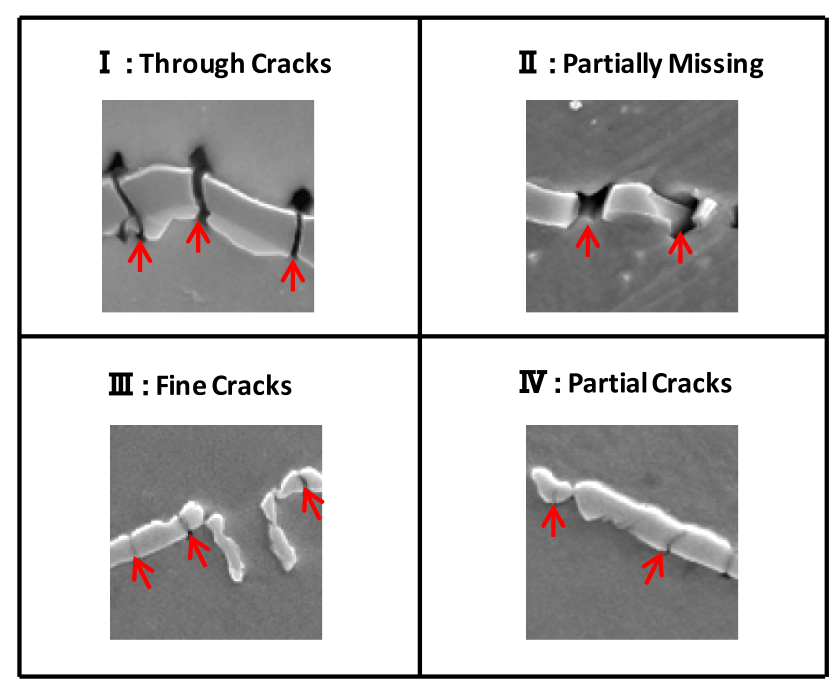

Fig. 15-Categorization of cracks in grain boundary.

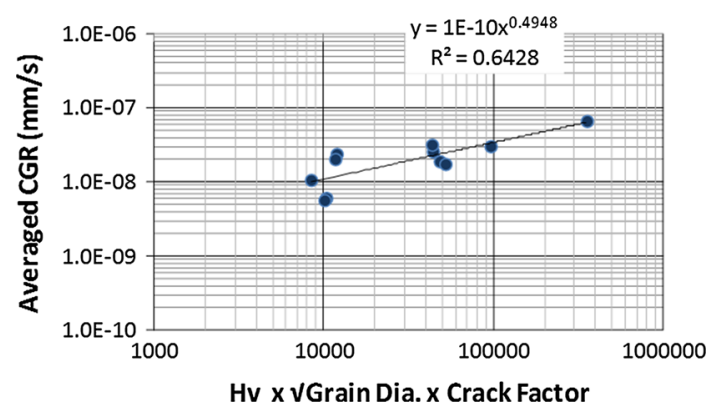

Fig. 16-Effect of hardness, grain size, and crack factor on averaged PWSCC growth rate in cold-worked TT Alloy 690 at $633 \mathrm{~K}$ $\left(360^{\circ} \mathrm{C}\right)$ in simulated PWR primary water.

Alloy 690. Many researchers ${ }^{[13-15,25,27]}$ have conducted PWSCCGR measurements on $\sim 30$ pct one directionally cold-rolled TT Alloy 690, which is why one-directional cold rolling of 30 pct was selected for comparison here. However, the strain-hardening level of materials for PWR components should really be evaluated from the Von Mises' equivalent strain, in which the 30 pct one directionally cold-rolled material is estimated as $60 \mathrm{pct}$ equivalent strain. ${ }^{[28]}$ For PWR components, the strainhardening level should be much lower, except mechanical plug for SG tube. Authors estimate that the strain-hardened level in the heat-affected zone of weld joint is less than 15 pct of von Mises' equivalent strain (less than about 8 pct cold rolling). Thus, in order to evaluate the PWSCCGR for strain-hardened materials in real PWR components, the estimate coming from the 15 pct cold-rolled TT Alloy 690 CGR data should be conservative. In Figure 13, the PWSCCGR of $15 \mathrm{pct}$ cold-rolled commercial TT Alloy 690 at $633 \mathrm{~K}\left(360{ }^{\circ} \mathrm{C}\right)$ was observed to be less than $6 \times 10^{-9} \mathrm{~mm} / \mathrm{s}$ (or $<0.2 \mathrm{~mm}$ per year).

Andresen et al..$^{[29]}$ and Tolozcko et al. ${ }^{[16]}$ reported the high SCCGR data on the highly cold-worked S-Loriented TT Alloy 690 specimens including CRDM materials. But, in case of real component as CRDM,

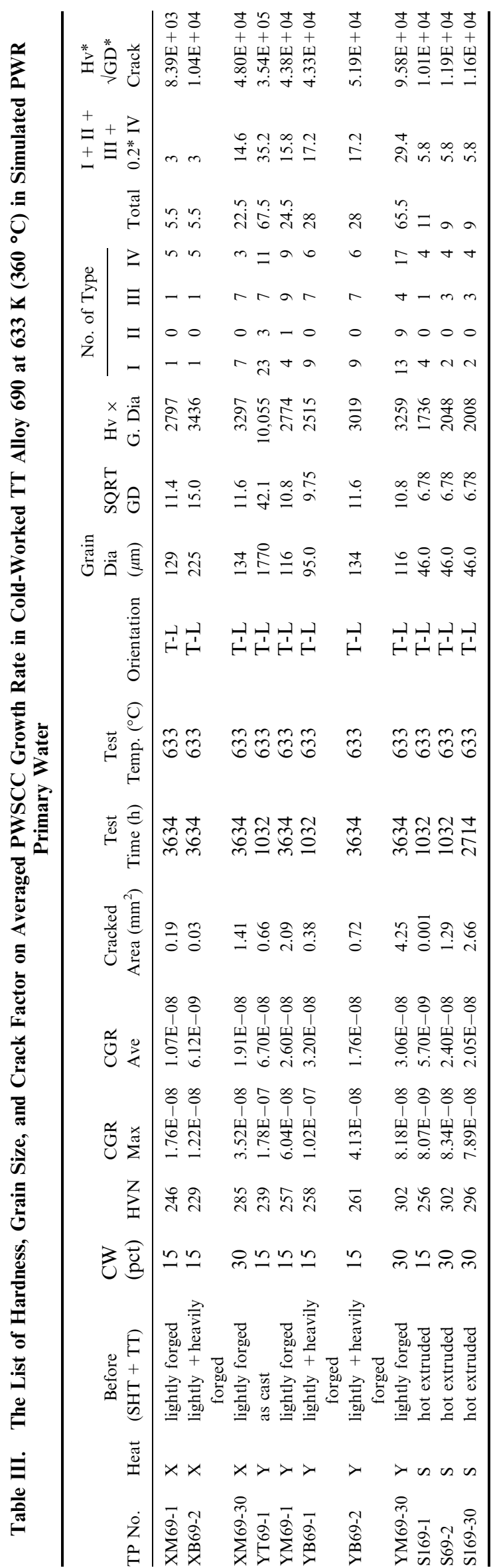

METALLURGICAL AND MATERIALS TRANSACTIONS A 
highly cold-worked material is not applied and also S-L orientation is not exposed to PWR primary water. From the above data in this paper, therefore, the high PWSCCGRs measured in highly cold-rolled TT Alloy 690 are deduced not to be an accurate tool for predicting the possibility of crack growth in forged TT Alloy 690 components such as CRDM nozzles.

\section{CONCLUSIONS}

This study was conducted to confirm the PWSCC propagation rate characteristics in highly cold-worked TT Alloy 690 exposed to PWR primary water and to clarify the mechanism of high growth rates. This paper has summarized the effect of metallurgical factors on PWSCCGRs in TT Alloy 690 in simulated PWR primary water.

Microcracks of carbides and voids were observed in or near eutectic $\mathrm{M}_{23} \mathrm{C}_{6} \mathrm{~GB}$ carbides (primary carbides) after cold rolling TT Alloy 690 heat A (that had been subjected to light forging during earlier processing) and Heat Y (that simulated the material used in the study by Paraventi et al. with heavy forging during processing). However, microcracks and voids in or near carbides along GBs were rarely detected in the cold-rolled commercial heat of TT Alloy 690 used for CRDM penetrations.

The density of primary $\mathrm{M}_{23} \mathrm{C}_{6} \mathrm{~GB}$ carbides and TiN in TT Alloy 690 was dependent on the chemical composition and fabrication processing.

The PWSCCGRs in cold-rolled TT Alloy 690 were different for each heat and fabrication process examined.

It is concluded that PWSCCGRs in cold-rolled TT Alloy 690 are affected not only by the hardness (or cold working ratio) but also by the grain size and the cracking of primary $\mathrm{M}_{23} \mathrm{C}_{6}$ carbides, whose presence and number strongly depend on the chemical composition and fabrication process.

It is deduced that the high PWSCCGRs observed in highly cold-rolled TT Alloy 690 are not representative of the practical situation with TT Alloy 690 components in PWR service for CRDM nozzles and other forged components.

\section{ACKNOWLEDGMENTS}

Part of this study was performed as a part of a collaborative research program that was financially supported by the Hokkaido Electric Power Company, the Kansai Electric Power Company, the Shikoku Electric Power Company, the Kyushu Electric Power Company, and also endowed by Mitsubishi Heavy Industries, Ltd. Some of the test material was supplied by NSSMC (Sumitomo Metal). The remaining part of this study was supported by JSPS KAKENHI Grant Number 22360396. The authors would like to acknowledge their financial support.

\section{OPEN ACCESS}

This article is distributed under the terms of the Creative Commons Attribution License which permits any use, distribution, and reproduction in any medium, provided the original author(s) and the source are credited.

\section{REFERENCES}

1. H.R. Copson: Physical Metallurgy of Stress Corrosion Fracture, Interscience, New York, 1959.

2. H. Coriou, L. Grall, Y. Le Gall, and S. Vettier: Third Metallurgy Conference on Corrosion, Saclay, North Holland and Publishing Co., Amsterdam, 1959, pp. 161-69.

3. H. Coriou, L. Grall, M. Pelras, and S. Vettier: Colloquium of the European Society of Atomic Energy, Studsvick, Sweden, 1962.

4. H. Coriou, L. Grall, C. Mahieu, and M. Pelras: Corrosion, 1966, vol. 22, pp. 280-90.

5. H. Coriou, L. Grall, P. Olivier, and H. Willermoz: Proceedings of the Conference on "Fundamental Aspects of Stress Corrosion Cracking", Columbus, 1968, Ohio State University, 1969, pp. 352-59.

6. H. Schenk: Corrosion 75, 1975, Paper No. 115.

7. S.J. Green and J.P.N. Paine: Proceedings of the International Symposium on Environmental Degradation of Materials in Nuclear Power Systems-Water Reactors, Myrtle Beach, SC, August 22-25, 1983, pp. 53-68.

8. W.H. Bamford and N.A. Palm: Proceedings of the Fourteenth International Conference on Environmental Degradation of Materials in Nuclear Power Systems Water Reactors, 2009, pp. 1525-36.

9. T. Yonezawa, K. Onimura, N. Sasaguri, T. Kusakabe, H. Nagano, K. Yamanaka, T. Minami, and M. Inoue: Proceedings of the Second International Symposium on Environmental Degradation of Materials in Nuclear Power Systems-Water Reactors, Sept. 9-12, Monterey, CA, 1985, pp. 593-600.

10. T. Yonezawa, K. Onimura, N. Sasaguri, T. Kusakabe, H. Nagano, K. Yamanaka, T. Minami, and M. Inoue: Proceedings of the International Symposium on Contribution of Materials Investigation to the Resolution of Problems Encountered in PWR Plants, Royal Abbey of Fontevraud, Sept. 2-6, 1985, pp. 289-96.

11. T. Yonezawa, K. Fujimoto, H. Kaguchi, and S. Asada: Proceedings of the 2005 PWSCC of Alloy 600 International Conference and Exhibit Show, Tamaya Resort, Santa Ana Pueblo, NM, March 7$10,2005$.

12. T. Yonezawa: "Ni Alloys" of Chapter 16, Comprehensive Nuclear Materials, Elsevier, Amsterdam, 2012.

13. K. Arioka, T. Yamada, T. Miyamoto, and T. Terachi: Proceedings of the International Conference Fontevraud 7, Sept. 26-30, 2010.

14. D.J. Paraventi and W.C. Moshier: Workshop on Cold Work in Iron and Nickel Base Alloys Exposed to High Temperature Water Environments, Mississauga, June 3-8, 2007.

15. P. Andresen, M. Mora, A. Ahluwalia, and J. Wilson: Proceedings of the $14^{\text {th }}$ International Conference on Environmental Degradation of Materials in Nuclear Power Systems-Water Reactors, Aug. 2327, Virginia Beach, VA, 2009, pp. 846-87.

16. M.B. Toloczko, M.J. Olszta, and S.M. Bruemmer: Proceedings of the $15^{\text {th }}$ International Conference on Environmental Degradation of Materials in Nuclear Power Systems-Water Reactors, Aug. 7-11, Colorado Springs, CO, 2011, pp. 91-106.

17. M.B. Toloczko, M.J. Olszta, and S.M. Bruemmer: Proceedings of the $15^{\text {th }}$ International Conference on Environmental Degradation of Materials in Nuclear Power Systems-Water Reactors, Aug. 7-11, Colorado Springs, CO, 2011, pp. 225-43.

18. D.R. Tice, S.L. Medway, N. Platts, and J.W. Stairmand: Proceedings of the $15^{\text {th }}$ International Conference on Environmental Degradation of Materials in Nuclear Power Systems-Water Reactors, Aug. 7-11, Colorado Springs, CO, 2011, pp. 71-87.

19. B. Alexandreanu, Y. Chen, K. Natesan, and B. Shack: Proceedings of the $15^{\text {th }}$ International Conference on Environmental Degradation of Materials in Nuclear Power Systems-Water Reactors, Aug. 7-11, Colorado Springs, CO, 2011, pp. 179-96.

20. Q. Peng, T. Shoji, J. Hou, Y. Takeda, and T. Yonezawa: Proceedings of the $15^{\text {th }}$ International Conference on Environmental 
Degradation of Materials in Nuclear Power Systems-Water Reactors, Aug. 7-11, Colorado Springs, CO, 2011, pp. 149-58.

21. P. Andresen, M. Mora, and A. Ahluwalia: Proceedings of the International Conference Fontevraud 7, Sept. 26-30, 2010.

22. T. Yonezawa: EPRI MRP Expert Panel Alloy 690 Meeting, Tampa, FL, Dec. 2-4, 2009.

23. T. Yonezawa, T. Horiuchi, N. Sato, and A. Hashimoto: EPRI MRP Expert Panel Alloy 690 Meeting, Tampa, FL, Nov. 29-Dec. 2, 2011.

24. T. Yonezawa: Proceedings of the $16^{\text {th }}$ International Conference on Environmental Degradation of Materials in Nuclear Power SystemsWater Reactors, Aug. 11-15, Ashville, NC, CD-Rom, 2013.

25. K. Arioka, T. Yamada, T. Miyamoto, and T. Terachi: Corrosion, 2011, vol. 67 (3), pp. 035006-1-18.
26. P. Andresen, P.W. Emigh, M.M. Morra, and R.M. Horn: Proceedings of the $11^{\text {th }}$ International Conference on Environmental Degradation of Materials in Nuclear Power Systems-Water Reactors, Aug. 10-14, Stevenson, WA, 2003, pp. 816-33.

27. S. Bruemmer, M. Olszta, and M. Toloczko: Proceedings of the International Conference Fontevraud 7, Sept. 26-30, 2010.

28. T. Yonezawa, T. Maeguchi, T. Goto, and H. Juan: Proceedings of the $15^{\text {th }}$ International Conference on Environmental Degradation of Materials in Nuclear Power Systems-Water Reactors, Aug. 7-11, Colorado Springs, Colorado, 2011, pp. 1759-71.

29. P. Andresen, M.M. Morra, and K. Ahluwalia: Proceedings of the $16^{\text {th }}$ International Conference on Environmental Degradation of Materials in Nuclear Power Systems-Water Reactors, Aug. 11-15, Ashville, NC, CD-Rom, 2013. 